\title{
CONDUTA DIETOTERÁPICA PARA PACIENTE COM GASTRITE CRÔNICA E OSTEOPOROSE: RELATO DE CASO
}

\section{CONDUCT DIET THERAPEUTIC FOR PATIENT WITH CHRONIC GASTRITIS AND OSTEOPOROSIS: CASE REPORT}

\section{Juliane ZENI'1 ; Patrícia CHICONATTO2; Vania SCHMITT²; Caryna Eurich MAZUR²}

1 - Nutricionista. Faculdade Campo Real.

2 - Nutricionista. Docente do Colegiado de Nutrição - Faculdade Campo Real.

Autor para correspondência: juli.zeni@hotmail.com

\section{RESUMO:}

O objetivo do presente trabalho foi relatar um caso clínico com base na conduta dietoterápica em paciente com gastrite crônica e osteporose. Trata-se de um estudo de caso clinico. Avaliado de maneira retrospectiva longitudinal. $O$ caso foi coletado de prontuário da paciente C.E.M. do sexo feminino de 48 anos moradora na cidade de Pitanga - PR. Os dados foram analisados das consultas $1^{\text {a }}$ consulta, $4^{\text {a }}$ consulta e $7^{\text {a }}$ consulta, no período de março de 2012 a novembro de 2013. O levantamento foi através de avaliação clínica, antropométrica, dietética e também de dietoterapia adequada ao caso, observando a melhora do seu quadro clínico e da qualidade de vida da paciente em questão. Houve melhora nos meses de consulta com atenuação dos sinais e sintomas assim como do prognóstico das doenças apresentadas.

Palavras-chave: Gastrite. Osteoporose. Menopausa. Avaliação Nutricional.

\section{ABSTRACT:}

The aim of this study was to report a clinical case based on dietotherapeutic conduct in a patient with chronic gastritis and osteporose. Based a study of a clinical case. Reviewed longitudinal retrospective. The case was collected from medical records of CEM female 48year resident patient in the city of Pitanga - PR, Brazil. Data were analyzed consultations 1st consultation, 4th and 7th consultation consultation, from March 2012 to November 2013. The survey was through clinical, anthropometric, dietary and proper diet therapy to the case, noting the improvement of their clinical picture and the patient's quality of life in question. An improvement in the months of consultation with signs and symptoms mitigation, as well as the prognosis of disease appear.

Keywords: Gastritis. Osteoporosis. Menopause. Nutritional Assessment.

\section{INTRODUÇÃO}

A gastrite crônica é comum na população como um todo, especialmente na meiaidade até o envelhecimento. A inflamação da mucosa gástrica pode ser apenas superficial e, portanto, não sendo muito perigosa, ou pode penetrar profundamente a mucosa, e, em casos de longa duração, causar atrofia quase completa da mucosa gástrica. Em alguns episódios, a gastrite pode ser aguda e intensa, com escoriação ulcerativa da mucosa 
gástrica pelas próprias secreções do estômago. Sugere-se que grande parte dos casos de gastrite é causada por infecção bacteriana crônica, principalmente pela bactéria Helicobacter pylori. Isto costuma ser tratado com sucesso por um esquema medicamentoso intensivo de terapia antibacteriana (GUYTON; HALL, 2006; MINICIS et al., 2011).

As alterações epiteliais no estômago, a partir de uma simples gastrite, podem se tornar displasias e constituir uma base para o desenvolvimento de carcinoma. Assim, a gastrite crônica é manifestada por padrões de alterações histológicas no organismo (FAUSTO, 2005).

Em contrapartida, a osteoporose é uma doença com incidência alta, especialmente entre o sexo feminino, ela atinge uma em cada três mulheres acima dos 50 anos e um em cada oito homens no mundo. No Brasil, afeta 9,5 milhões de pessoas. Cerca de 200 mil pessoas morrem todos os anos no país em decorrência destas fraturas. Com o aumento da expectativa de vida, este número tende a crescer caso a população não se conscientize e comece a cuidar mais do seu corpo e da sua saúde óssea (SBEN, 2014).

A osteoporose é uma doença esquelética sistêmica, caracterizada por massa óssea baixa e deterioração microarquitetural do tecido ósseo, conduzindo à fragilidade do osso e ao aumento do risco de fratura. Na menopausa aumenta a renovação e diminui a formação óssea em cada unidade de remodelação, o que pode conduzir à uma perda de massa óssea. O risco de osteoporose depende tanto da massa óssea máxima alcançada nos anos da idade adulta jovem quanto do índice de perda da massa nas épocas posteriores. O pico de massa óssea geralmente não é alcançado antes de 30 anos e o estilo de vida é um importante determinante da probabilidade de desenvolver mais tarde osteoporose. Não se sabe ao certo em que idade inicia-se a perda óssea, mas acredita-se que, entre 40 anos e a menopausa, as mulheres perdem aproximadamente $0,3 \%$ a $0,5 \%$ de sua massa de osso cortical por ano; após a menopausa, este ritmo acelera para $2 \%$ a $3 \%$ ao ano (LUCASIN JUNIOR; LIMA, 1994; SOUZA, 2010).

Diante da importância do estudo das doenças supramencionadas, torna-se significativa a realização do presente estudo. O objetivo do mesmo foi relatar um caso clínico com base na conduta dietoterápica em paciente diagnosticado clinicamente com gastrite crônica e osteoporose.

\section{MATERIAL E MÉTODOS}

Trata-se de um estudo de caso clínico. Avaliado de maneira retrospectiva longitudinal. 
O caso clínico foi coletado de prontuário da paciente conduzido em âmbito ambulatorial, atendida por uma nutricionista em serviço de Personal Diet. Este estudo foi associado à revisão da literatura sobre $\mathrm{o}$ assunto em questão.

Foram avaliados os prontuários da $1^{\circ}, 4^{\circ}$ e $7^{\circ}$ consulta de acompanhamento (março de 2012 a novembro de 2013), dados encontrados entre as consultas também foram considerados.

Os dados foram avaliados de maneira descritiva. Com avaliação nutricional completa (figura 1).

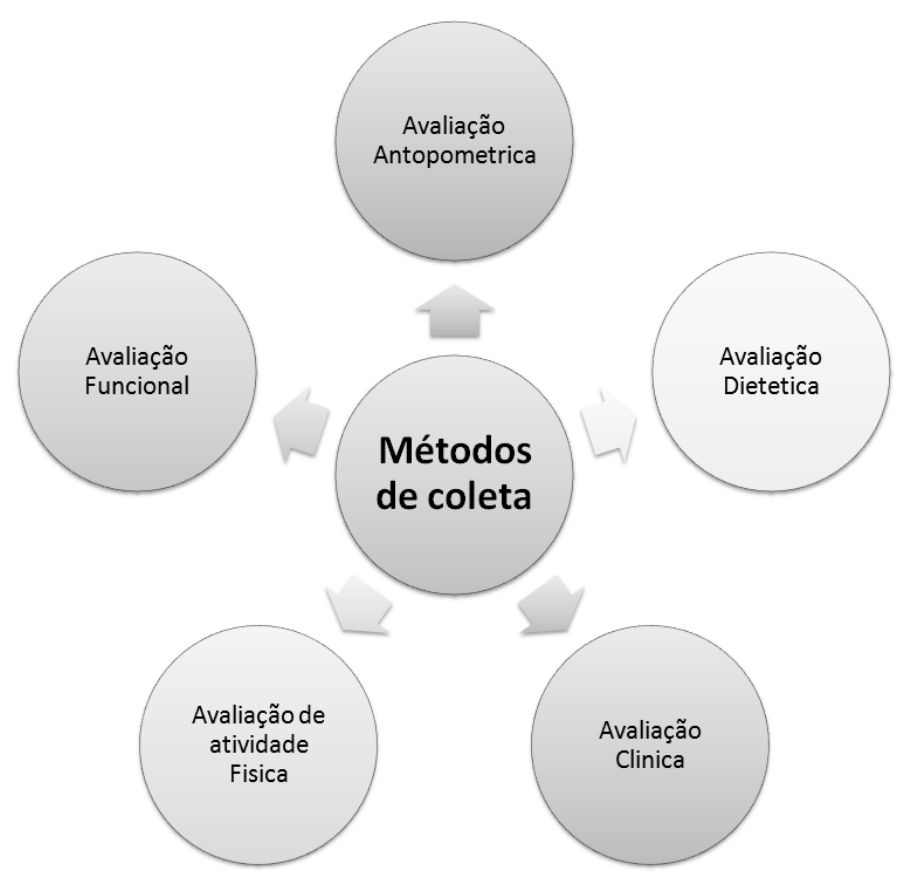

Figura I - Métodos utilizados para a coleta de dados da paciente

\subsection{Avaliação antropométrica}

Os parâmetros usados para avaliação foram peso e altura utilizando balança mecânica Filizola® com capacidade de 150 quilos, e com estadiômetro acoplado à balança, para aferição da altura. A circunferência do braço (CB) foi determinada por uma fita métrica no ponto médio entre o acrômio e olécrano a mensuração das pregas cutâneas tricipital (PCT), bicipital (PCB), subescapular (PCSE) e suprailíaca (PCSI) foi realizada com auxílio de adipômetro científico Cescorf $\AA$, de acordo com parâmetros preconizados por Frisancho (1981;1990) e Lohman (1988). Os seguintes parâmetros foram calculados: Índice de Massa Corporal (IMC) e classificado conforme protocolo da Organização Mundial da Saúde (2000), circunferência muscular do braço (CMB), adequação de PCT (\%PCT) e adequação de CB 
(\%CB), assim como o percentual de gordura corpórea (\%GC), conforme preconizado com Lohman (1988). Por meio da balança com bioimpedância Plenna® foram obtidos os dados de massa magra (MM).

\subsection{Avaliação dietética}

As necessidades estimadas de energia foram definidas como valor médio de ingestão de energia proveniente da dieta, conforme o recordatório de 24h (R24h) coletado da paciente.

O R24h é uma entrevista realizada pela nutricionista onde o entrevistado descreve o consumo de alimentos e bebidas nas últimas $24 \mathrm{~h}$ ou do dia anterior. As quantidades consumidas foram estimadas em medidas usuais ou caseiras, unidades ou porções de alimentos e transformadas posteriormente, em gramas (FISBERG et al., 2005; ROSSI, 2008).

\subsection{Avaliação clínica}

Foi realizada por meio de relato de medicamentos administrados e os tratamentos das doenças que a paciente apresentava.

O método empregado para a medida da pressão arterial (PA) foi o indireto, com técnica auscultatória, sendo aferida pela própria nutricionista responsável pela paciente. Foi utilizado esfigmomanômetro Aneróide Premium $\AA$, certificado pela Sociedade Brasileira de Cardiologia, com tolerância de $3 \mathrm{mmHg}$. A PA foi aferida no braço direito da paciente na posição sentada, após pelo menos cinco minutos de descanso. Para efeito de análise foi considerada a média de três aferições, com intervalo de 30 minutos após cada aferição, com correção para o perímetro braquial.

\subsection{Avaliação de atividade física}

Foi verificado em todas as consultas se a paciente praticava atividade física, o tipo de atividade, bem com sua intensidade e duração.

\subsection{Avaliação funcional}

O objetivo da avaliação funcional foi identificar sinais e sintomas que poderiam estar 
associados às deficiências de nutrientes específicos e às anormalidades nutricionais. Nessa avaliação a nutricionista recorreu à inspeção visual, à palpação, à percussão e à ausculta (WIDTH e REINHARD, 2011).

Foi avaliada quanto ao exame físico a coloração da pele, inclusive nas regiões palmares e das mucosas, principalmente conjuntival e labial, detecção da palidez. Para verificação de possível desidratação foram avaliados os seguintes sinais, produção de saliva da paciente, verificou-se o brilho dos olhos, a tensão ocular e a umidade das mucosas (DUARTE, 2007).

\subsection{Avaliação dos resultados}

A paciente assinou termo de consentimento livre e esclarecido e foi informada sobre essa pesquisa e seus objetivos. Este é um relato de prontuário, portanto foram considerados dados secundários, sem a intervenção da equipe de pesquisadores. Os resultados foram apresentados e avaliados de maneira descritiva.

\section{RESULTADOS E DISCUSSÃO}

\subsection{Identificação do paciente, história clínica e medicamentosa}

Paciente C.E.M, sexo feminino, 48 anos, moradora na cidade de Pitanga, Paraná, trabalhava como pedagoga, casada, com dois filhos. Paciente apresentava quadro de osteoporose femoral e lombar, diagnosticada em junho de 2012 por meio de densitometria óssea, além de gastrite crônica de fundo e antro. Iniciou o tratamento nutricional em março de 2012.

Paciente procurou atendimento nutricional para tratamento de gastrite $\mathrm{e}$ posteriormente foi diagnosticada com osteoporose na quarta consulta.

O quadro de gastrite já acontecia há 15 anos, a paciente controlava com tratamento medicamentoso.

A partir da $3^{\text {a }}$ consulta (13/05/2012) a paciente começou com medicação prescrita pelo ortopedista: alendronato de sódio $(70 \mathrm{mg} / \mathrm{dia})$ em jejum. $\mathrm{O}$ medicamento causava irritação gastrintestinal. $\mathrm{Na}$ consulta seguinte, a nutricionista solicitou ao médico a alteração do horário do medicamento, passando a ser depois do café da manhã. Desde a primeira consulta a paciente administra Omeprazol®, sem efeitos colaterais posteriores e 
intercorrências. Além disso, na 4⿳a consulta, paciente relatou a administração de pantopracal sódico $(20 \mathrm{mg} / \mathrm{dia})$ em jejum. Ainda, na $2^{\underline{a}}, 4^{\underline{a}}$ e $5^{\underline{a}}$ consultas a paciente relatou a ingestão de Ibuprofeno (100mg/dia), pois apresentou quadro de febre grave.

Sabe-se que a administração de Omeprazol® tem como principal característica a inibição da bomba de prótons gástrica, como interação deste medicamento há diminuição de ferro, vitamina B12 e diminuição de secreção do ácido gástrico (REIS, 2004).

No que diz respeito à administração de alendronato de sódio, para tratamento da osteoporose, sabe-se que esse medicamento é um inibidor específico da reabsorção óssea. $\mathrm{Na}$ absorção, sofre interferência com leite e derivados, bebidas ou suplementos com alto teor de cálcio e antiácidos (VIANA, 2010). A suplementação de cálcio teve a indicação, no caso, devido às doenças apresentadas pela paciente, menopausa e osteoporose.

Considerado um dos processos inflamatórios mais frequentes no ser humano, a gastrite pode ser encontrada nas formas aguda e crônica. A gastrite tanto pode ser assintomática quanto poderá ocorrer epigastralgia e até indigestão, como no caso da paciente. Sugere-se que a infecção bacteriana da mucosa gástrica é a causadora da maioria das gastrites e outras pesquisas apontam que $95 \%$ dos casos de gastrites crônicas têm como agente etiológico a bactéria H. pylori (BLACK, 2002).

A osteoporose tem sido recentemente reconhecida como um dos maiores problemas de saúde pública (ENGERMANN et al., 2005). Atingindo cerca de um terço das mulheres na pós-menopausa, tornou-se uma das doenças osteometabólicas mais comuns, sendo responsável por alto índice de morbidade e mortalidade entre as pessoas mais velhas, com enormes repercussões sociais e econômicas, provocando grande impacto na qualidade de vida e grau de independência nos indivíduos acometidos (FORSBACH; SANTOS, 1994; TEIXEIRA NETO, 2009).

A paciente praticou atividade física, caminhadas e musculação a partir da quarta consulta. Também praticava pilates cerca de 3 vezes por semana e ioga com intensidade leve em 2 vezes na semana. Considera-se o objetivo principal de qualquer abordagem terapêutica na osteoporose a prevenção de fraturas por meio da atividade física. Além da promoção da manutenção óssea, o exercício físico proporciona outros benefícios, como: preservar e melhorar a força muscular; aliviar as dores e manter a flexibilidade; evitar maiores deformidades e desvios posturais; melhorar o condicionamento físico; melhorar o equilíbrio e a marcha; e manter as atividades de vida diária (FLECK; SIMÃO, 2008).

Segundo Sousa e Pinto (2012), diversos tratamentos têm sido utilizados objetivando aumento/manutenção da densidade mineral óssea. Entre eles estão à terapia 
de reposição hormonal, o uso de compostos bifosfonatos, controle nutricional e a atividade física.

Mulheres na faixa dos 30 aos 55 anos confirmam que os exercícios físicos podem melhorar o quadro de osteopenia originada pela queda na produção de estrógeno (TEIXEIRA, 2008).

\subsection{Conduta nutricional e evolução dos resultados}

A paciente avaliada apresentou mudanças no seu IMC entre as consultas com variáveis de média $19,87 \pm 0,32 \mathrm{~kg} / \mathrm{m}^{2}$. Sendo na primeira consulta apresentou o IMC de $19,5 \mathrm{~kg} / \mathrm{m} 2$ na quarta consulta IMC $20 \mathrm{~kg} / \mathrm{m} 2$, na sétima consulta $20,1 \mathrm{~kg} / \mathrm{m} 2$ obtendo o diagnóstico de eutrofia em todas as consultas (Gráfico I).

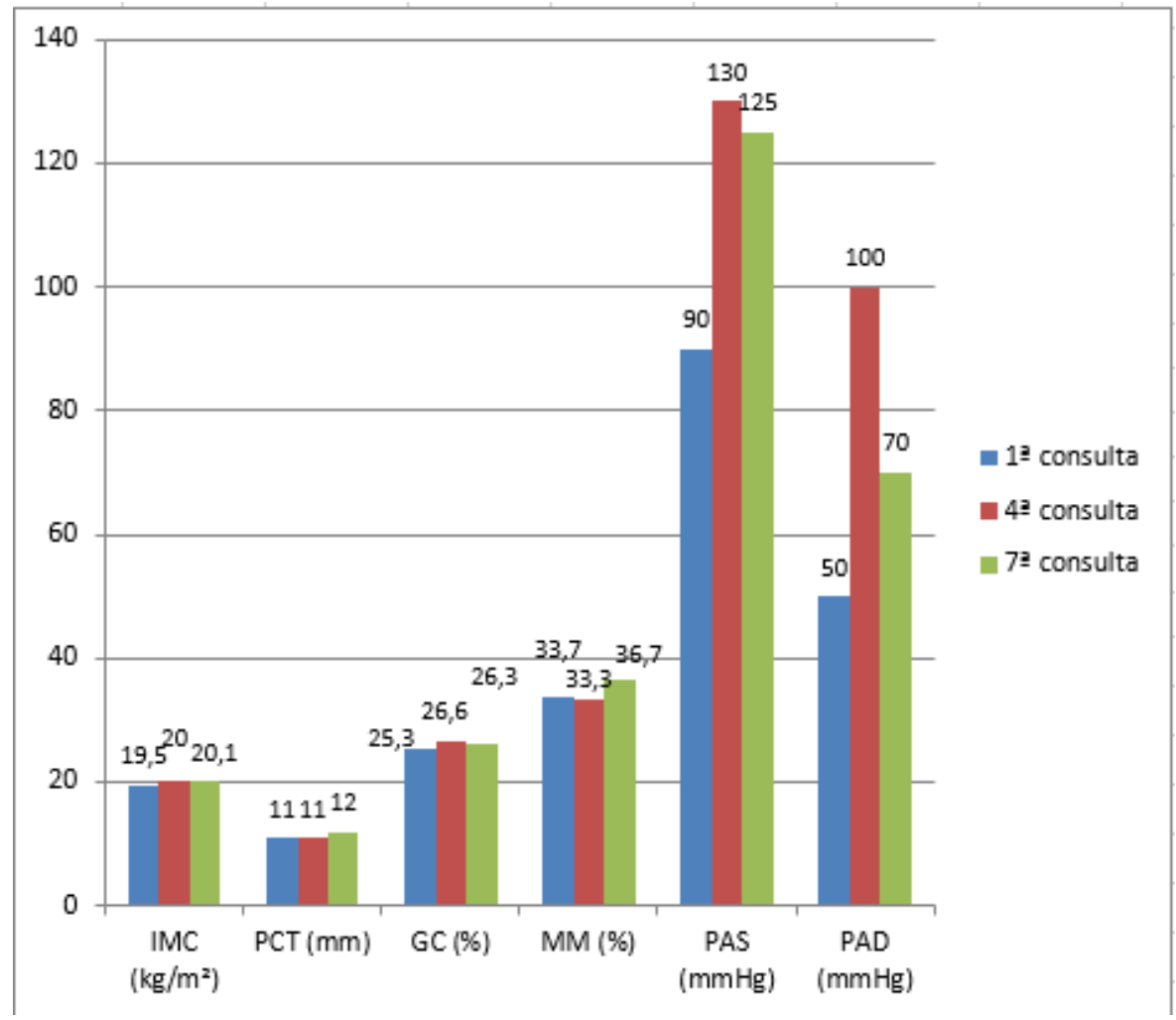

GRÁFICO 1 - Evolução nutricional da paciente por meio dos parâmetros de Índice de Massa Corporal (IMC), Prega Cutânea Tricipital (PCT), Gordura Corporal (GC), Massa Magra (MM), Pressão Arterial Sistólica (PAS) e Pressão Arterial Diastólica (PAD)

Nota-se que houve um aumento de peso, porém a paciente sempre manteve-se eutrofica. Esse aumento foi importante pois houve melhora da imunidade, dos quadros de 
infecção recorrente e o adequado fornecimento de calorias conforme estabelecido pelas necessidades nutricionais da paciente.

Pode-se observar mudanças na PCT, com média entre as 3 consultas de $10,72 \pm 0,71 \mathrm{~mm}$. Na primeira consulta apresentou $11 \mathrm{~mm}$ mantendo na quarta consulta e houve mudança na sétima, com $12 \mathrm{~mm}$. O diagnóstico final foi de 47,05\% de adequação, apresentando desnutrição grave segundo Blackburn e Thornton (1979).

A gordura corporal (GC) está associada à boa saúde e aptidão física. O excesso pode contribuir para muitas doenças, inclusive as cardiovasculares, e, normalmente, está relacionada com a ingestão excessiva de calorias ou perda de massa magra. O \%GC de acordo com Lohman et al. (1988) classifica-se acima da média, para mulheres de 46 a 55 anos. De acordo com o gráfico pode-se observar que na primeira consulta a soma apresentou $25,3 \%$ na quarta $26,6 \%$ e sétima consulta $26,3 \%$.

A MM é composta principalmente por água, músculos, órgãos, células sanguíneas e ossos, sendo o único tecido que promove gasto energético corporal (calorias). Sua diminuição pode indicar inadequação alimentar ou de atividade física. O percentual de MM na paciente foi em média de $35,2 \pm 2,12 \mathrm{~kg}$. Na primeira e quarta consulta manteve entre $33,7 \mathrm{~kg}$ a $33,3 \mathrm{~kg}$, no entanto verificou-se posteriormente o valor de $36,7 \mathrm{~kg}$ na última consulta.

De acordo com a tabela 1, em relação ao fornecimento de quilocalorias diárias (kcal/dia) a média foi de 2360,33 $\pm 129,82 \mathrm{kcal}$, tendo aumentado entre as consultas na primeira consulta e sétima (2470 kcal), pois com a evolução do peso sua ingestão de energia também aumentou.

TABELA I - Variáveis dietéticas obtidas com relação à alimentação da paciente

\begin{tabular}{ccccc}
\hline Variáveis Dietéticas & 1 $^{\text {a }}$ consulta & 4⿻ consulta & 7ª $^{\text {a }}$ consulta & Média \pm DP \\
\hline kcal/dia & 2217 & 2394 & 2470 & $2360,33 \pm 129,82$ \\
Carboidrato (\%) & 65,83 & 65,06 & 61,32 & $64,07 \pm 2,41$ \\
Proteína (\%) & 14,08 & 20,68 & 21,44 & $18,73 \pm 4,05$ \\
Lipídio (\%) & 20,09 & 14,26 & 17,24 & $17,20 \pm 2,92$ \\
Cálcio (mg) & 724,6 & 827,9 & 1002,4 & $851,63 \pm 140,41$ \\
\hline
\end{tabular}


Os carboidratos são produzidos pelos tubérculos, raízes, grãos e cereais em geral e são uma importante fonte de energia na dieta, abrangendo cerca da metade do total de calorias. O consumo de carboidrato pela paciente foi em média $64,07 \pm 2,41 \%$. Na evolução das consultas, pode-se observar uma diminuição devido o alto valor de carboidrato ingerido pela paciente.

A ingestão de proteínas varia individualmente entre 50 a $100 \mathrm{~g}$ dia, sendo grande parte da proteína consumida de origem animal. Conforme dados apresentados pela paciente a quantidade aumentou entre consultas devido a sua necessidade, pela recuperação muscular e aumento da proteína devido à sugestão de suplementação de Whey Protein (30 g/dia), o que ocorreu a partir da 4⿳⺈ responsável relatou que a recomendação de suplementação foi em consequência da perda constante de massa óssea da paciente, também, devido à reposição protéica e constituição da MM para adequado funcionamento do organismo principalmente na atividade física realizada pela paciente.

O lipídio constitui aproximadamente $34 \%$ da energia na dieta dos seres humanos. Como a gordura é rica em energia e fornece $9 \mathrm{kcal} / \mathrm{g}$, os seres humanos são capazes de obter energia adequada com um consumo diário razoável de alimentos que contém gordura. Na primeira consulta a paciente ingeria $20,9 \%$ na quarta diminuiu para $14,26 \%$, por fim, na sétima consulta apresentou $17,24 \%$ de lipídios em sua alimentação diária.

O cálcio é o mineral mais abundante no organismo, constitui cerca de $1,5 \%$ a $2 \%$ do peso corporal e $39 \%$ de todos os minerais do corpo. O consumo de cálcio para a paciente precisou obter quantidade suficiente para manter a integridade e saúde óssea. Através de dados da primeira consulta o cálcio consumido na alimentação foi de 724,6 mg, na quarta consulta de $827,9 \mathrm{mg}$ e na última $1002,4 \mathrm{mg} /$ dia sendo o valor adequado por meio das recomendações para mulheres, no qual a indicação é $1000 \mathrm{mg} / \mathrm{dia}$.

Em relação ao exame físico, no início do acompanhamento nutricional a paciente apresentou hipocoloração da pele e mucosas (conjuntival e labial), além da face pálida. A nutricionista sugeriu, a partir das observações, um quadro de deficiência de ferro, após isso solicitou exame bioquímico de hemograma completo. Retornando em consultas posteriores foi notado que havia diminuição da hemoglobina e hematócrito, sugestivo de anemia ferropriva. A nutricionista encaminhou a paciente para médico com o objetivo da verificação do quadro clínico. Após a suplementação de sulfato ferroso e adequação da alimentação oferecida quanto ao ferro e vitamina $\mathrm{C}$, a paciente retornou na quarta consulta com resultados bons, constatados diante de exames bioquímicos e físico nutricional. 
Segundo Cançado e Chiattone (2010), o quadro de anemia na menopausa é raro, salvo em casos em que há sangramento, principalmente gastrintestinal devido a doenças destes órgãos. Há ainda, a depleção da reserva de ferro na menopausa, o que tem etiologia multifatorial - redução da secreção ácida gástrica ou trânsito intestinal acelerado, entre outras causas.

A paciente procurou tratamento nutricional, também, em virtude da sintomatologia da gastrite crônica que foi diagnosticada a mais de dez anos. Os quadros de azia, má digestão e vômitos foram atenuados no decorrer das consultas, e a nutricionista optou no inicio por uma alimentação branda evoluindo de acordo com a aceitação e diminuição dos sintomas da paciente.

No início da gastrite, o hábito alimentar saudável se faz totalmente necessário para a diminuição e cicatrização das lesões da mucosa gástrica, além disso, ajudou a diminuir o risco de se adquirir a bactéria $H$. pylori, porque, as alterações que ocorrem nas células podem ser revertidas, muitas vezes após a erradicação da bactéria, mudanças na dieta e estilo de vida (RUBIN, 2006).

Além da menopausa, existem outros fatores de risco para ocorrer à osteoporose, como a influência genética, tabagismo, utilização elevada de cafeína, dieta inadequada em cálcio e sedentarismo. O controle dos fatores de risco é a principal estratégia para evitar os problemas decorrentes da osteoporose. Nesse aspecto, a prática regular de exercícios físicos é uma das principais providências sugeridas (POLITO, 2010).

Além dos dados apresentados, a paciente passou a fazer uso de probióticos, cultura de bactérias lácteas, a partir da $4^{a}$ consulta, o que causou melhora no trânsito intestinal, verificado segundo dados relatados pela paciente em consulta subsequente. Considera -se que algumas culturas probióticas podem ser benéficas para a manutenção da saúde gástrica (ANTUNES et al., 2007; TEIXEIRA NETO, 2009). Michetti (2001) sugere o emprego de Lactobacillus acidophilus associado à antibioticoterapia no combate ao patógeno $H$. pylori.

\section{CONCLUSÃO}

A intervenção nutricional foi primordial para a manutenção e recuperação do estado nutricional da paciente em estudo, como a adequação dietética ao longo do tempo, a melhora dos parâmetros antropométricos e do exame físico. Torna-se importante a inserção da dietoterapia no tratamento de gastrite crônica e osteoporose já instaladas e em sua 
prevenção. Denota-se o valor ao atendimento nutricional para o alcance das necessidades nutricionais, as quais podem repercutir na melhoria da qualidade de vida, na resposta ao tratamento e na sintomatologia das enfermidades apresentadas. O diagnóstico nutricional deve ser precoce, tanto na gastrite como na osteoporose, e o monitoramento do estado nutricional é um dever de todos os profissionais de saúde.

\section{REFERÊNCIAS}

ANTUNES, A.E.C.; SILVA, E.R.A.; MARASCA, E.T.G.; MORENO, I.; LERAYER, A.L.S. Probióticos: agentes promotores de saúde. Nutrire, v. 32, n. 3, p. 103-122, dez. 2007.

BLACK, J.G Doenças orais e gastrintestinais. 4. ed. Rio de Janeiro: Guanabara Koogan, 2002.

BLACKBURN, G. L.; THORNTON, P. A. Nutritional assessment of the hospitalized patients. Medical Clinics of North America, v. 63, p. 1103-15, 1979.

CANÇADO, R.D.; CHIATTONE, C.S. Anemia ferropênica no adulto - causas, diagnóstico e tratamento. Revista Brasileira de Hematologia e Hemoterapia, v.32, n.3, 2010.

CARVALHO, C.M. Educação para a saúde em osteoporose com idosos de um programa universitário: repercussões. Cadernos de Saúde Pública, v.9, n.1, p. 27-38, 2004.

DUARTE, A.C.G. Avaliação nutricional: aspectos clínicos e laboratoriais. São Paulo: Atheneu, 2007.

ENGERMANN, M.; SCHNEIDER, E.; EVANS, C.H.; BALTZER, A.W The potential of gene therapy for fracture healing in osteoporosis. Osteoporosis International, v.15, n. 1, p. 82-7, 2005.

FAUSTO, N.; MITCHELL, R. N. Patologia: Bases Patológicas das doenças. Rio de Janeiro: Elsevier, 2005.

FISBERG, R.M.; MARTINI, L.A.; SLATER, B. Métodos de inquéritos alimentares. In: FISBERG, R.M.; SLATER, B.; MARCHIONI, D.M.L.; MARTINI, L.A. Inquéritos alimentares: métodos e bases científicos. São Paulo: Manole; 2005. p. 1-31. 
FLECK, S.; SIMÃO, R. Força: Princípios metodológicos para o treinamento. São Paulo: Phorte, 2008.

FORSBACH, G.; SANTOS, A. Densidad óssea yosteporosis: una opinion. Ginecologia and Obstetricy. v.62, p. 201-3, 1994.

FRISANCHO, A.R. Anthopometric Standards for the Assessment of Growth an Nutritional Status. Ann Arbor, Mich: University of Michigan Press, 1990.

FRISANCHO, A.R. New norms of upper limb fat and muscle áreas for assessment of nutritional status. American Journal of Clinical Nutrition, v. 34, p. 2540-45, 1981.

GUYTON, A.C; HALL, J.E. Tratado De Fisiologia Médica. Rio de Janeiro: Elsevier, 2006.

LANZILLOTTI, H.S.; LANZILLOTTI, S.R.; TROTTE, A.P.R. et al. Osteoporose em mulheres na pós-menopausa, cálcio dietético e outros fatores de risco. Revista de Nutrição, v.16, n.2, 2003.

LOHMAN, T. G.; ROCHE, A. F.; MARTORELL, R. Anthropometric standardization reference manual. Human Kinetics: Champaign, 1988.

LUCASIN R.Jr.; LIMA, W.L. Osteoporose: exercício como prevenção e tratamento. Arscvrandi: A Revista da Clínica Médica, p.28-36, 1994.

MICHETTI, P. Lactobacilli for the management of Helicobacter pylori. Nutrition, v. 17, n. 3, p. 268-269, 2001.

MINICIS, M.; MINICIS, R.; MINICIS, R. Avanços no tratamento da bactéria Helicobacter pylori (HP). Gastroenterologia Endoscópica Digestiva, v.30, n.2, p.75-79, 2011.

POLITO, M.D. Prescrição de exercícios para saúde e qualidade de vida. São Paulo: Phorte, 2010.

REIS, N.T. Nutrição Clínica. Interações. Rio de Janeiro- RJ: Roca, 2004. 
ROSSI, L. Avaliação nutricional: novas perspectivas. São Paulo: Roca, 2008.

RUBIN E. Patologia: Bases Clínico Patológicas em Medicina. Rio de Janeiro: Guanabara Koogan, 2006.

SOCIEDADE BRASILEIRA ENDOCRINOLOGICA E METABOLOGIA (SBEN). Disponível em: <http://www.endrocrino.org.br>. Acesso em 22 mar. 2014.

SOUZA, M.P.G. Diagnóstico e tratamento da osteoporose. Revista Brasileira de Ortopedia, v.45, n.3, 2010.

TEIXEIRA NETO, F. Nutrição Clinica. Rio de Janeiro: Guanabara Koogan, 2009.

TEIXEIRA, L. Atividade Física Adaptada e Saúde: da teoria à prática. São Paulo: Phorte, 2008.

VIANA, D.P. Compacto guia de medicamentos com cuidados de enfermagem. São Caetano do Sul, SP: Yendis Editora, 2010.

WIDTH, M; REINHARD, T. Mds: Manual De Sobrevivência Para Nutrição Clinica. Rio de Janeiro: Guanabara Koogan, 2011.

WORLD HEALTH ORGANIZATION. Obesity: preventing and managing the global epidemic; Report of a WHO consultation. World Health Organization Technical Report Series, v.894, p. 1-253, 2000. 